\title{
Association of Self-Reported Quality of Life in Children with Level of Bronchial Asthma Control
}

\author{
Shalini Verma ${ }^{\circledR 1}$, Shally Awasthi ${ }^{\circledR 2}$, Sarika Gupta ${ }^{\circledR 3}$ \\ ${ }^{1}$ Senior Resident, Department of Pediatrics, KGMU, Lucknow, Uttar Pradesh, India, ${ }^{2}$ Professor \& Head, Department of Pediatrics, KGMU, Lucknow, Uttar Pradesh, India, \\ ${ }^{3}$ Associate Professor, Department of Pediatrics, KGMU, Lucknow, Uttar Pradesh, India.
}

\section{Abstract}

Background: To assess the association of self-reported quality of life (QOL) by using mini- pediatric asthma quality of life questionnaire (mini-PAQLQ) in children aged between 7-15 years with a level of asthma control. Subjects and Methods: Prospective observational study conducted in the asthma clinic in the outpatient department from September 2016 to August 2017. All the cases of asthma, as defined by GINA guidelines, aged between 7-15 years with parental consent were recruited. The level of control was also assessed according to GINA guidelines. Excluded were clinically suspected cases of chronic lung diseases except for bronchial asthma and any other chronic medical condition. QOL was assessed by using mini-PAQLQ which had three domains i.e. Symptoms, emotions and limitation of activity. Each domain had questions and their responses coded on a visual scale with 7 options. Results: From September 2016 to August 2017, total enrolled were 85 of which 51 $(60 \%)$ were partly controlled and 34(40\%) were well controlled. Mean mini-PAQOL score in patients with partly control was low (3.59 \pm 0.93$)$ as compared to those with well-controlled asthma $(5.83 \pm 1.21)(\mathrm{p}=0.0001)$. Conclusion: Self-reported QOL of children with partly controlled asthma was found to be impaired in all the domains as compared to those with well-controlled asthma.

Keywords: Pediatric Asthma, Outpatient, Level of Control, Quality of Life, India

Corresponding Author: Shalini Verma, Senior Resident, Department of Pediatrics, KGMU, Lucknow, Uttar Pradesh, India.

E-mail: drshalinikgmu@gmail.com

Received: 6 April 2020

Revised: 11 May 2020

Accepted: 19 May 2020

Published: 9 July 2020

\section{Introduction}

Asthma is a chronic, heterogeneous, inflammatory disorder of the small airways leading to obstruction of the airflow, which may be completely or partially reversed with or without specific asthma therapy. The pathophysiology includes role of genetic and environmental factors resulting in airway inflammation. ${ }^{[1]}$ In asthma, recurrent attacks of inflammation of the airways leading to airway hyperactivity or bronchial hyperresponsiveness (BHR), defined as the inherent tendency of the airway to narrow the response of environmental allergens or irritants. ${ }^{[2]}$ Repeated airway inflammation causes structural and functional changes in the airway and that can result in bronchospasm, mucosal edema and mucus plug and eventually ventilation-perfusion mismatch. The susceptible individual may present with recurrent episodes of breathlessness, cough, wheezing, and chest tightness particularly in the night (or early morning) or after exercise. ${ }^{[3,4]}$

Globally around 334 million people are estimated to be suffering from asthma. ${ }^{[5]}$ Global Initiative for Asthma (GINA) estimated the prevalence of asthma in different countries ranging from 1 to $18 \%$ of the population. ${ }^{[6]}$ The prevalence of asthma has increased in children all over the world as well as in India. ${ }^{[7]}$ The prevalence of asthma in Indian children was studied by the International Study of Asthma and Allergy in Children (ISAAC) and reported to be ranging from $5.35 \%$ to $6.05 \%{ }^{[8]}$ The prevalence of asthma is three times higher in boys than girls before puberty but it becomes equal during adolescence. ${ }^{[9]}$

GINA has developed criteria for diagnosis, level of control and management protocol for adults and children older than 5 years. ${ }^{[10]}$ Asthma control is divided into wellcontrolled, partly controlled and uncontrolled according to GINA guidelines. ${ }^{[11]}$ Childhood asthma is delivering a substantial burden to the patient, their parents and society. Limitation of activities (47\%), absence from school (23-51\%) and sleep disturbance (up to $34 \%$ ) has been reported in childhood asthma. ${ }^{[3,12]}$ Asthma is ahead of all chronic illnesses in children in terms of school absenteeism, healthcare visits, hospitalization and lost workdays by parents. ${ }^{[13]}$ Childhood asthma substantially impacts the physical, emotional and psychosocial part of children's lives. Apart from signs and 
symptoms of asthma, it also affects their biological functions, mental state, peer relationship and negative social perceptions, which end up changing the quality of life of children and their families. ${ }^{[14]}$

So the objective of the study was to assess the association of self-reported QOL by using mini- paediatric asthma quality of life questionnaire (mini-PAQLQ) in with level of asthma control in children aged 7-15 years attending ambulatory care asthma clinic.

\section{Subjects and Methods}

The study was done in the Department of Paediatrics, King George's Medical University, Lucknow, a tertiary care center from September 2016 to August 2017 after obtaining ethical clearance from the institute's ethics committee. This was a prospective observational study. We included children between 7 to 15 years, visiting the outdoor Asthma clinic. While inclusion, we ignored clinically suspected cases of allergic rhinitis due to its strong comorbid association with bronchial asthma. ${ }^{[15]}$ Bronchial asthma was diagnosed based on GINA guidelines. ${ }^{[6,10]}$ These were symptoms of asthma such as wheeze, shortness of breath, chest tightness, cough and documented use of bronchodilators. We excluded clinically suspected cases of chronic lung diseases except for bronchial asthma and any other chronic medical conditions. Informed written consent was obtained from one or both parents for participation. Assent was taken from children who were 8 years of age or older.

Data was collected on a predesigned questionnaire having sections for demography, clinical variables and QOL of a child by using the mini Paediatric Asthma Quality of life Questionnaire (mini-PAQLQ).

\section{Assessment of Quality of Life}

The pediatric asthma quality of life questionnaire (PAQLQ) is a specific instrument to assess the quality of life among children aged 7 to 17 years. It has 23 items under three domains: symptoms (10 items), emotional function ( 8 items) and activity limitation (5 items). All items scored on a 7 point Linkert scale, ranging from 1 (severely affected) to 7 (unaffected). All the items are then added according to the domain and the mean score is calculated for the purpose of understanding. ${ }^{[16]}$ In this study, children suffering from asthma were administered the Hindi version of the MiniPAQLQ questionnaire [Figure 1]. The original questionnaire had 13 questions with higher scores indicating better QOL. One question was deleted from the questionnaire as it was not culturally appropriate. This question was "how much difficulty they had while spending time with their pets due to asthma in the last 7 days" since most children did not have any pets. Hence Mini-PAQLQ was adapted with 12 questions. Mini-PAQLQ scale had three domains- (i) Relief in Signs and Symptoms (6 Questions); (ii) Emotional Changes (4 questions); (iii) Limitation of Activities (2 questions) [Figure 1] Responses were coded on an analog visual scale with 7 options. For enhancing the quality of assessment, a questionnaire was administered by the same author in all children and that too after practice with similar results. Results were also checked in the first few children by repeated evaluation by another author.

\section{Assessment of level of control}

Well-controlled asthma was defined over last 4 weeks as, none or $\leq$ twice/week daytime symptoms, no limitation of activities, no nocturnal symptoms or awakening, need of reliever medication (salbutamol) for $\leq$ twice/week and Peak expiratory flow (PEF) or forced expiratory volume in 1 minute (FEV1) normal according to GINA guidelines. Partly controlled asthma was defined as >twice/week daytime symptoms, any limitation of activities, any nocturnal symptoms or awakening, the need of reliever/rescue for $>$ twice/week, PEF or FEV1 $<80 \%$ and exacerbations one or more/year according to GINA guidelines. Uncontrolled asthma was defined as three or more features of partially controlled asthma present in any week and exacerbation once in a week according to GINA guidelines. ${ }^{[6,10]}$

Data was computerized on Microsoft excel. Data were cleaned to identify correct entries and outliers. Continuous data were summarized as Mean \pm standard deviation (SD), while discrete (categorical) in number and Percentage (\%). Categorical variables were compared using the chi-square test and continuous variables using unpaired t-test. Using a two-tailed distribution a $p$-value of $<0.05$ was considered statistically significant.

\section{Sample size calculation}

Data were summarized using frequencies and percentages for categorical variables or means with standard deviation for measured variables. The mean QOL score in Indian children was found to be 4.660 with a standard deviation (SD) of 1.281 with a variation of $20 \%$ and an alpha level of 0.05 , then the sample size should be at least $80 .{ }^{[17,18]}$

\section{Results}

Our study was conducted between September 2016 to August 2017. Flowchart of recruitment is given as Figure-2. During this time 96 patients were screened, 11 were excluded and 85 patients were enrolled in the study. Of these $34(40 \%)$ had well-controlled and $51(60 \%)$ had partly controlled asthma. There was no case of uncontrolled asthma. Among the 85 recruited cases, 55 cases $(64.7 \%)$ were males and 30 cases $(35.3 \%)$ were females. 65 cases $(76.5 \%)$ were between $7-10$ years and $20(23.5 \%)$ were between $11-15$ years.

\section{Quality of Life}




\title{
बच्चों में दमा - जीवन की गुणवत्ता पर संक्षित्त प्रश्नावली (MiniPAQLQ)
}

\section{साक्षात्कारकर्ता-संचालित \\ (INTERVIEWER-ADMINISTERED) HINDI VERSION FOR INDIA}

\author{
(C) 2011
}

QOL TECHNOLOGIES LId.

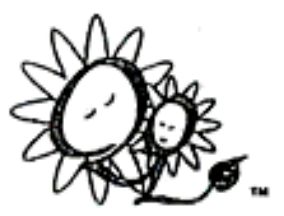

For further information:

Elizabeth Juniper, MCSP. MSc

Professor

20 Marcuse Fields

Bosham, West Sussex

PO18 8NA, England

Telephone: $\$ 441243572124$

Fax: $\$ 441243573680$

E-mail: juniper@qoltech.co.uk

Web: http://www.qoltech.co.uk

This translation has been made pósisible through a grant from QOL Technologies Ltd

- Translated by MAPI INSTITUTE Senior Translator: Roohi Khan

(C) बच्चों में दमा - जीवन की गुणवता पर संक्षिप्त प्रश्नावली (MiniPAQLQ) कोपीराइटिड है और इसके सर्वाधिकार सुरक्षित हैं। इस प्रश्नावली के किसी भी भाग का विक्रय, परिवर्तन, या प्रतिकृति किसी भी रूप में QOL. Technologies Limited के लिए Elizabeth Juniper की लिखित अनुमति के बिना नहीं किया जाना चाहिए।

सितम्बर 2011 


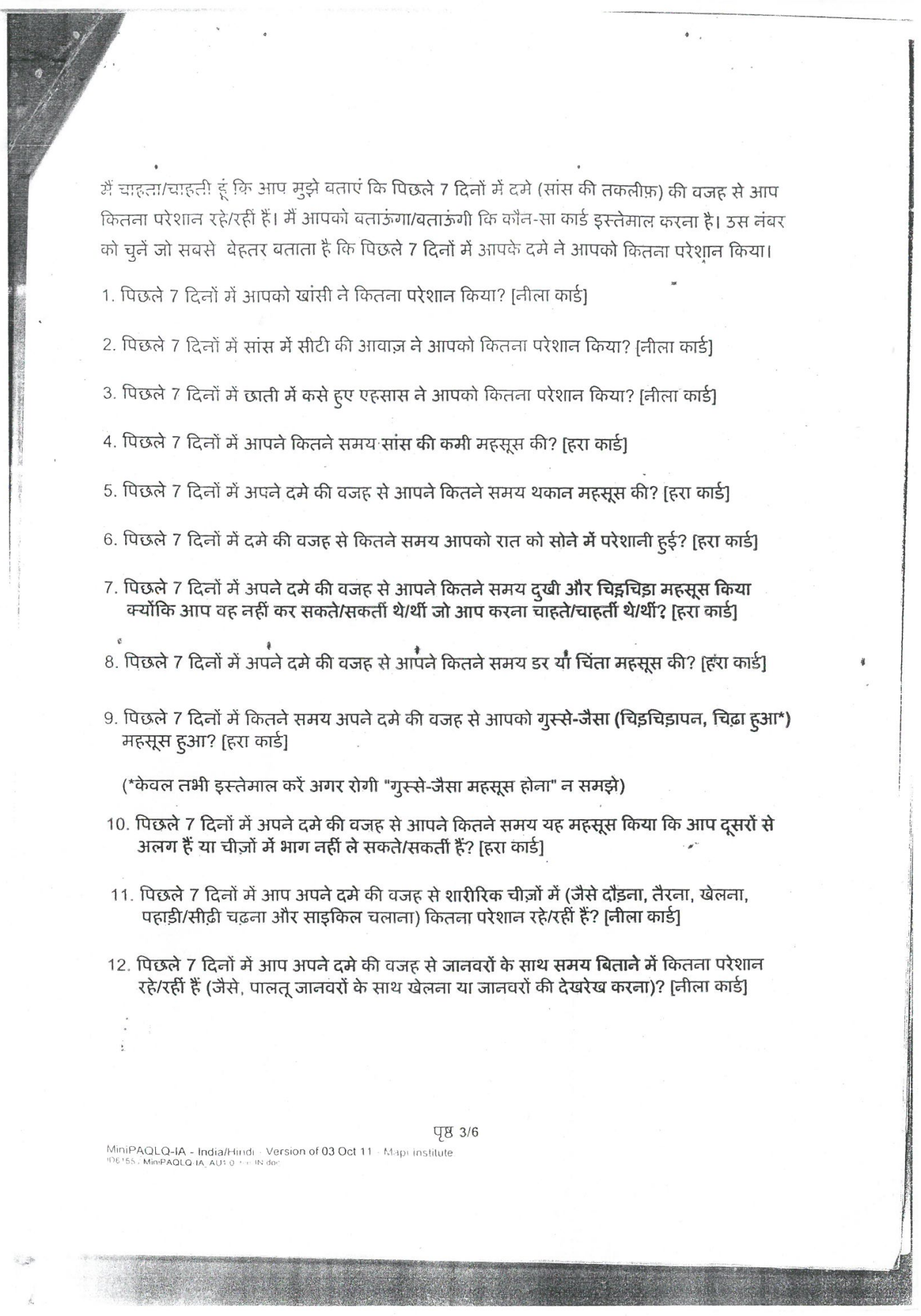

Figure 2: Flowchart of recruitment 


\begin{tabular}{|l|llllll|}
\hline \multicolumn{7}{|l|}{ Table 1: Association of various domains of QOL scores and total QOL Score with Level of control } \\
\hline Level of Control & No. (\%) & Symptoms & Emotions & $\begin{array}{l}\text { Limitation } \\
\text { Activity }\end{array}$ & of & Total QOL \\
& & Mean (SD) & Mean (SD) & Mean (SD) & Mean (SD) \\
\hline Partly controlled & $51(60)$ & $3.49(1.10)$ & $3.77(0.80)$ & $3.52(0.89)$ & $3.59(0.93)$ \\
\hline Well controlled & $34(40)$ & $5.37(1.15)$ & $5.96(1.17)$ & $6.16(1.32)$ & $5.83(1.21)$ \\
'p' value & & 0.0001 & 0.0001 & 0.0001 & 0.0001 \\
\hline
\end{tabular}

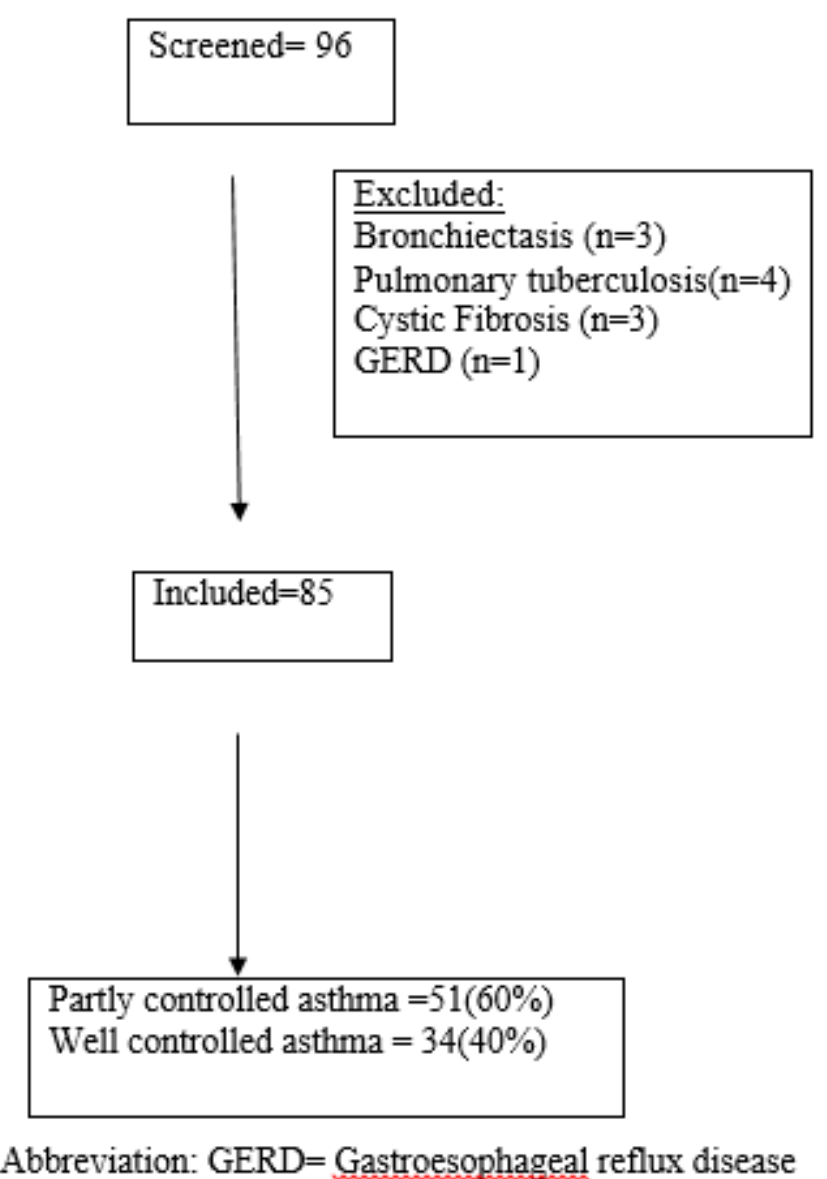

Figure 4: Flow chart for the study

Table 2: Association of QOL scores among younger (7-10 years) and older (11-15 years) pediatric age group

\begin{tabular}{lll}
\hline Pediatric Age Group & No. & Mean (SD) \\
Younger (7-10 years) & 65 & $4.18(0.99)$ \\
& $(76.5)$ & \\
Older (11-15 years) & 20 & $4.32(1.01)$ \\
& $(23.5)$ & \\
\hline 'p' value & 0.5835 & \\
\hline
\end{tabular}

Scores in the domains of Symptoms, Emotions, Limitation of activity were $4.71 \pm 1.65,3.74 \pm 0.86$ and $4.67 \pm 1.63$ respectively. Mean total QOL 3.59 \pm 0.93 . Total QOL for younger children (7-10 years) was $4.18 \pm 0.99$ and for older children (11-15 years) was $4.32 \pm 1.01$. Table- 1 shows the association of QOL with the level of asthma control. It was found that in all 3 domains of QOL as well as in total, well-controlled asthmatics scored better than partly controlled ones. 
3. पिछले 7 दिनों में आप अपने दमे की वजह से दोस्तों और घरवालों के साथ की जाने याली चीज्ञों (जैसे, रिसेस में खेलना और अपने दोस्तों और घरवालों के साथ कोई चीज़ करना) में कितना परेशान रहे/रहीं हैं? [नीला काई ]

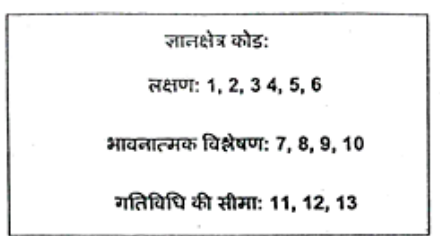

Figure 3: Hindi version of Mini-PAQLQ Questionnaire

Mean QOL for younger children (7-10 years) was 4.18 \pm 0.99 and for older children (11-15 years) was $4.32 \pm 1.01$. Table2 shows the association of QOL in a different pediatric age group. There is no significant difference in QOL was found in both younger and older children group.

\section{Discussion}

This was a prospective observational study carried out to assess self -reported QOL by using mini-PAQLQ in children between 7-15 years with partly and well-controlled asthma attending an outpatient clinic in the department of Paediatrics. We found that self-reported QOL was statistically significantly better in children with well-controlled asthma as compared to those with partly controlled asthma. In this study miniPAQLQ developed by Juniper et al. (1998) was used. ${ }^{[19,20]}$ Mini PAQLQ is a valid, reliable and easy to administer tool for the children's age group. ${ }^{[21-23]}$ It had three domains -Relief in Signs and Symptoms, Emotional Changes and Limitation of activities. The total quality of life score was assessed by summing the above scores. We customized mini-PAQLQ to Indian culture by removing one question from limitation in the activity domain.

In our study, QOL of children with partly controlled asthma is compromised as compared to those with well-controlled asthma in all three domains. This finding corroborates with the finding of other studies done in Indian children. Nair s. et al found QOL was compromised in children with exacerbation of asthma. ${ }^{[17]}$ Wander A et al from India, found that the children who had a history of poorly controlled asthma had less overall mean score when compared to those who had good control. ${ }^{[21]}$ Similar results have been reported from Greece and Turkey where better asthma control leads better QOL in children. ${ }^{22,23]}$

Unlike our findings, Nair S.et al, found no significant difference in the emotional domain of QOL between cases of well-controlled and partly controlled asthma. Wander A et al, found that children who had partial control on asthma reported more impairment in the emotional domain than in symptoms and activity limitations domain. ${ }^{[17,21]}$

In this study, we also did not found a significant change in the quality of life between the younger age group (7-10 years) and older age group (11-15 years) children. Saad S. Al Zahrani et al, studied the impact of bronchial asthma on QOL among affected children and compared QOL of age group 7-11 and 12-17 year and found no significant difference. ${ }^{[24]}$ Similarly, a study by Wander A et al, measured the quality of life using PAQLQ among 90 asthmatics in age group 7-17 years and found no significant change in PAQLQ scores in the age ranges of 7 to 12 years $(4.92 \pm 0.87)$ and 13 to 17 years $(5.02 \pm 0.80)^{[21]}$

This was a cross-sectional study and no follow up was done to see if QOL improved with improvement in control. However, we have recruited cases prospectively from the asthma outpatient clinic. We used standard definition as asthma, hence there are limited chances of misclassification of asthma. We also used an internationally validated asthma specific QOL scale which makes our work generalizable. The limitation may be, we did not get any children under the uncontrolled asthma category. The reason for this may be that we have recruited all cases from an out-patient asthma clinic and it is unlikely to report uncontrolled cases in the outdoor as most cases of uncontrolled asthma directly reach the in-patient and emergency services.

\section{Conclusion}

We concluded that the Self-reported QOL of children with partially controlled asthma was statistically significantly lower as compared to those with well-controlled asthma. Hence effective management of all asthmatic children must be done to achieve control over symptoms.

\section{References}

1. Ege MJ, Mayer M, Normand AC, Genuneit J, Cookson WOCM, Braun-Fahrländer C, et al. Exposure to Environmental Microorganisms and Childhood Asthma. New Engl J Med. 2011;364(8):701-709. Available from: https://dx.doi.org/10. 1056/nejmoa1007302.

2. Rajan S, Gogtay NJ, Konwar M, Thatte UM. The global initiative for asthma guidelines (2019): change in the recommendation for the management of mild asthma based on the SYGMA-2 trial - A critical appraisal. Lung India. 2020;37:169-73. Available from: https://dx.doi.org/10.4103/ lungindia.lungindia_308_19.

3. Fuhlbrigge AL, Guilbert T, Spahn J, Peden D, Davis K. The Influence of Variation in Type and Pattern of Symptoms on Assessment in Pediatric Asthma. Pediatr. 2006;118(2):619625. Available from: https://dx.doi.org/10.1542/peds.20052963. 
4. Bousquet J, Clark TJH, Hurd S, Khaltaev N, Lenfant C, O'Byrne $\mathrm{P}$, et al. GINA guidelines on asthma and beyond. Allergy. 2007;62(2):102-114. Available from: https://dx.doi. org/10.1111/j.1398-9995.2006.01305.x.

5. Asher I, Pearce N. Global burden of asthma among children. Int J Tuberc Lung Dis. 2014;18:1269-1278. Available from: https://dx.doi.org/10.5588/ijtld.14.0170.

6. Masoli M, Fabian D, Holt S, and RB. The global burden of asthma: executive summary of the GINA Dissemination Committee Report. Allergy. 2004;59(5):469-478. Available from: https://dx.doi.org/10.1111/j.1398-9995.2004.00526.x.

7. Pal R, Dahal S, Pal S. Prevalence of Bronchial Asthma in Indian Children. Indian J Community Med. 2009;34(4):310-316. Available from: https://dx.doi.org/10.4103/0970-0218.58389.

8. Singh S, Sharma BB, Sharma SK, Sabir M, and VS. Prevalence and severity of asthma among Indian school children aged between 6 and 14 years: associations with parental smoking and traffic pollution. J Asthma. 2016;53(3):238-244. Available from: https://dx.doi.org/10.3109/02770903.2015.1087558.

9. Bjornson B. Farm equipment industry performance: past and future. Int Food Agribus Man. 2000;3:71-84. Available from: https://dx.doi.org/10.1016/s1096-7508(00)00028-8.

10. Asthma GI, For. Asthma is Different in Women. Curr Allergy Asthma Rep. 2015;15(6):28. Available from: https://dx.doi. org/10.1007/s11882-015-0528-y.

11. Koshak EA. Classification of asthma according to revised 2006 GINA: Evolution from severity to control. Ann Thoracic Med. 2007;2:45-45. Available from: https://dx.doi.org/10. 4103/1817-1737.32228.

12. Wildhaber J, Carroll WD, Brand PLP. Global impact of asthma on children and adolescents' daily lives: The room to breathe survey. Pediatr Pulmonol. 2012;47(4):346-357. Available from: https://dx.doi.org/10.1002/ppul.21557.

13. Becker AB, Abrams EM. Asthma guidelines. Curr Opin Allergy Clin Immunol. 2017;17:99-103. Available from: https: //dx.doi.org/10.1097/aci.0000000000000346.

14. Merikallio VJ, Mustalahti K, Remes ST, Valovirta EJ, Kaila M. Comparison of quality of life between asthmatic and healthy school children. Pediatr Allergy Immunol. 2005;16(4):332340. Available from: https://dx.doi.org/10.1111/j.1399-3038. 2005.00286.x.

15. Sharma S, Shrama R, Sharma M, Verma M. Association between Bronchial asthma and Allergic Rhinitis: A Crosssectional Study. Int J Public Health. 2016;2:32-37.

16. Juniper EF, Guyatt GH, Feeny DH, Ferrie PJ, Griffith LE, Townsend M. Measuring quality of life in children with asthma. Qual Life Res. 1996;5(1):35-46. Available from: https://dx.doi. org/10.1007/bf00435967.
17. Nair S, Nair S, Sundaram KR. A prospective study to assess the quality of life in children with asthma using the pediatric asthma quality of life questionnaire. Indian J Allergy Asthma Immunol. 2014;28(1):1-13. Available from: https://dx.doi.org/ 10.4103/0972-6691.134210.

18. Bhalerao S, Kadam P. Sample size calculation. Int J Ayurveda Res. 2010;1(1):55-59. Available from: https://dx.doi.org/10. 4103/0974-7788.59946.

19. Wing A, Upton J, Svensson K, Weller P, Fletcher M, Walker $\mathrm{S}$. The standardized and mini versions of the PAQLQ are valid, reliable, and responsive measurement tools. J Clin Epidemiol . 2012;65(6):643-50. Available from: https://dx.doi.org/10. 1016/j.jclinepi.2011.12.009.

20. Juniper EF, Guyatt GH, Feeny DH, Griffith LE, Ferrie PJ. Minimum skills required by children to complete healthrelated quality of life instruments for asthma: comparison of measurement properties. Eur Respir J. 1997;10(10):22852294. Available from: https://dx.doi.org/10.1183/09031936. 97.10102285.

21. Wander A, Bhargava S, Pooni PA, Kakkar S, Arora K. Quality of life in children with bronchial asthma. J Pediatr Res. 2017;4(06):382-389.

22. Kalyva E, Eiser C, Papathanasiou A. Health-Related Quality of Life of Children with Asthma: Self and Parental Perceptions. Int J Behav Med. 2016;23(6):730-737. Available from: https: //dx.doi.org/10.1007/s12529-016-9558-7.

23. Sari O, Aydogan U, Gulec M, Doganer YC, Yavuz ST. General and disease-specific scales in children with asthma and their parents. Indian Pediatr. 2017;54:25-27. Available from: https: //dx.doi.org/10.1007/s13312-017-0991-8.

24. Zahrani A, S S, Morsy E, A E, Dorgham LS, S L. The impact of bronchial asthma on quality of life among affected children and adolescents in Taif city, Saudi Arabia. Life Sci J. 2014;11(6):283-91.

Copyright: (C) the author(s), 2020. It is an open-access article distributed under the terms of the Creative Commons Attribution License (CC BY 4.0), which permits authors to retain ownership of the copyright for their content, and allow anyone to download, reuse, reprint, modify, distribute and/or copy the content as long as the original authors and source are cited.

How to cite this article: Verma S, Awasthi S, Gupta S. Association of Self-Reported Quality of Life in Children with Level of Bronchial Asthma Control. Asian J. Clin. Pediatr. Neonatol. 2020;8(2):16-22.

DOI: dx.doi.org/10.47009/ajcpn.2020.8.2.4

Source of Support: Nil, Conflict of Interest: None declared. 